\title{
DISTRIBUIÇÃO ESPACIAL DA MATÉRIA ORGÂNICA, GRAU DE FLOCULAÇÃO E ARGILA DISPERSA EM ÁGUA EM ÁREA DE VEGETAÇÃo NATURAL EM REGENERAÇÃO E PASTAGEM ${ }^{1}$
}

\author{
Julião Soares Souza Lima², Gustavo Soares de Souza³ e Samuel de Assis Silva ${ }^{4}$
}

\begin{abstract}
RESUMO - Este experimento objetivou analisar as alterações no comportamento espacial dos atributos do solo: matéria orgânica (MO), argila dispersa em água (ADA) e grau de floculação (GF) em áreas ocupadas com vegetação natural em regeneração e em pastagem. As amostras de solo foram coletadas na profundidade de 0,0-0,2 m em uma grade amostral com 64 pontos, espaçados $10 \mathrm{~m}$. Os dados foram submetidos à análise descritiva e, em seguida, foi realizada a análise geoestatística. Observaram-se os maiores valores para ADA e os menores valores de GF na área de pastagem. Todos os atributos apresentam dependência espacial para as duas áreas em estudo, com ajuste dos modelos esférico e exponencial. A confecção dos mapas temáticos por meio da krigagem ordinária permitiu melhor visualização da distribuição espacial dos atributos de solo.
\end{abstract}

Palavras-chave: Variabilidade espacial; Krigagem; Uso do solo.

\section{SPATIAL DISTRIBUTION OF ORGANIC MATTER, DEGREE OF FLOCCULATION AND CLAY DISPERSED IN WATER IN A SOIL UNDER REGENERATING NATURAL VEGETATION AND PASTURE}

\begin{abstract}
This experiment aimed to analyze changes in spatial behavior of the attributes of soil: clay dispersed in water $(C D W)$, degree of flocculation $(D F)$ and organic matter $(O M)$ in areas occupied by native vegetation in natural regeneration and pasture. Soil samples were collected at a depth of 0.0-0.2 $\mathrm{m}$ in a grid with 64 sampling points, spaced at $10 \mathrm{~m}$. The data were submitted to descriptive and geostatistics analysis. The highest values were observed for the $C D W$ and the lowest values of DF in the pasture. All attributes show spatial dependence for the two areas of study, with adjustment of the spherical and exponential models. The preparation of thematic maps using the ordinary kriging allowed better visualization of the spatial variability of soil attributes.
\end{abstract}

Keywords: Spatial variability; Kriging; Soil use.

\section{INTRODUÇÃO}

A ocupação do solo pelo homem provoca alterações associadas a práticas de manejo em graus variados sobre os atributos do solo. Dessa forma, a manutenção da qualidade dos solos é fundamental para o desenvolvimento de culturas e a garantia de níveis satisfatórios de produção.

A retirada da cobertura vegetal original e a implantação de culturas, aliadas às práticas de manejo inadequadas, promovem o rompimento do equilíbrio entre o solo e o meio, modificando seus atributos físicoquímico-biológicos, além de limitar sua utilização agrícola e torná-lo mais suscetível à erosão hídrica (CENTURION et al., 2001).

Pela própria natureza dos fatores responsáveis pela sua formação, o solo apresenta heterogeneidade em superfície e em profundidade, uma vez que seu material de origem não é uniforme em toda a sua extensão e não sofre o processo de intemperização de forma

\footnotetext{
${ }^{1}$ Recebido em 15.07.2011 aceito para publicação em 12.05.2013.

${ }^{2}$ Departamento de Engenharia Rural, Universidade Federal do Espírito Santo, Centro de Ciências Agrárias. E-mail: <limajss@yahoo.com.br>.

${ }^{3}$ Instituto Capixaba de Pesquisa, Assistência técnica e Extensão rural. E-mail: <gsdsouza@ hotmail.com>.

${ }^{4}$ Departamento de Ciências Agrárias e Ambientais, Universidade Estadual de Santa Cruz, UESC. E-mail: < samuelassis@hotmail.com>.
} 
homogênea e contínua (SOUZA et al., 2004). A ocupação de áreas por pastagens que antes eram ocupadas por vegetação natural tem se transformado em áreas degradadas, muitas vezes influenciadas pela pedoforma e ocupação sem critérios técnicos, levando a um manejo inadequado do solo.

Alguns autores têm demonstrado que os atributos de solo muitas vezes não revelam uma variação puramente aleatória ao longo de um terreno, apresentando correlação espacial (GOMES et al., 2007). Assim, a geoestatística tem sido utilizada como importante ferramenta de análise dos dados, a fim de modelar e estudar a estrutura de dependência espacial dos atributos do solo, por meio do ajuste de semivariogramas experimentais.

Investigar as causas dessa variabilidade é fator importante em um sistema de produção que vise ser sustentável, uma vez que a variabilidade espacial dos atributos do solo pode influenciar a eficiência do manejo das culturas (CORÁ et al., 2004). Essa variabilidade pode ser mais bem entendida quando em uma mesma unidade taxonômica se têm diferentes formas de ocupação do solo.

Nesse contexto, este trabalho teve como objetivo analisar a variabilidade espacial da matéria orgânica, o grau de floculação e a argila dispersa em água em um Argissolo Vermelho-Amarelo sob vegetação natural em regeneração e em pastagem utilizando técnicas de geoestatística.

\section{MATERIAL E MÉTODOS}

\subsection{Localização da área de estudo}

A área de estudo está localizada no Bioma Mata Atlântica, e sua vegetação natural constitui-se de Floresta Estacional Semidecidual, com relevo predominantemente acidentado, com declividade variando na sub-bacia entre $30 \mathrm{e} 45^{\circ}$ e altitude em torno de $150 \mathrm{~m}$, em um Argissolo Vermelho-Amarelo, com textura argilosa (EMBRAPA, 2006) apresentando os teores médios de areia, silte e argila de 340, 223 e $434 \mathrm{~g} \mathrm{~kg}^{-1}$, respectivamente. Essa área situa-se na Bacia Hidrográfica do Itapemirim, do córrego Horizonte, Município de Alegre, ES, nas coordenadas geográficas $20^{\circ} 46^{\prime} 2,8^{\prime \prime}$ de latitude Sul e 41 $27^{\circ}$ '39,2" de longitude Oeste. O clima da região, segundo a classificação de Köppen, é do tipo "Aw”, tropical quente úmido, com inverno frio e seco, temperatura anual média de $23,1^{\circ} \mathrm{C}$ e precipitação pluviométrica média anual de $1.341 \mathrm{~mm}$.

\subsubsection{Divisão da área quanto à cobertura do solo}

O terço médio de uma encosta de mesma unidade taxonômica foi dividido em duas áreas experimentais com diferentes ocupações do solo e as laterais distantes em $20 \mathrm{~m}$.

A primeira área é composta por um fragmento da Mata Atlântica em estado de regeneração natural há aproximadamente 30 anos, quando da coleta dos dados, constituindo um compartimento com pedoforma convexa, com ligeira mudança para côncava na extremidade inferior esquerda. Os principais representantes no extrato arbóreo são: o angico- canjiquinha (Peltophorum dubium), o ipê-felpudo (Zeyhera tuberculosa), o jacaré (Piptadenia communis) e o cinco-folhas (Sparattosperma vernicosum); no extrato arbustivo: o arranha-gato (Acacia spp.); e nas áreas mais abertas ocorre a incidência de capim-colonião (Panicum maximum) e outras gramíneas.

A segunda área é composta por uma pastagem implantada há seis anos com a espécie de Brachiaria decumbens, após o revolvimento do solo em nível com um arado de aivecas com tração animal. Na época da semeadura ocorreu aplicação de calcário dolomítico em cobertura, sem adubação. O sistema de pastejo é extensivo, com média anual de uma unidade animal por hectare, sendo maior concentração observada nos períodos de chuva, podendo chegar a três unidades de animal por hectare e menor concentração no período de estiagem.

\subsection{Amostragem e atributos do solo}

Em cada área experimental foi construída uma grade de amostragem contendo 64 pontos, com espaçamento de $10 \mathrm{~m}$ entre pontos. Para o processo de marcação dos pontos foram utilizados equipamentos de topografia e GPS. No cruzamento das linhas da grade, o solo foi coletado na profundidade de 0,0 - 0,2 m, com o auxílio de um trado tipo sonda, no mês de novembro. As análises foram realizadas no Laboratório de Física e Química do Solo do CCA/UFES.

Os atributos de solo analisados foram: a matéria orgânica (MO), a argila dispersa em água (ADA) e o grau de floculação (GF). O carbono orgânico total (COT) foi determinado em TFSA por oxidação em via úmida, utilizando-se solução de $\mathrm{K}_{2} \mathrm{CrO}_{7}$ em meio ácido 
(YEOMANS; BREMNER, 1988). A MO do solo foi estimada a partir dos valores de COT, admitindo-se que ele participa com $58 \%$ na composição da $\mathrm{MO}$ (EMBRAPA, 1999). A ADA foi estimada conforme EMBRAPA (1997), a partir da TFSA, utilizando-se agitação mecânica rápida e água destilada. O GF da argila foi calculado pela expressão [100*(argila total - argila dispersa em água)/argila total].

\subsection{Análises exploratória e descritiva}

Na análise exploratório-descritiva, os dados foram submetidos à verificação de presença de outliers e sua influência quanto às medidas de posição e de dispersão, antes de submetê-las à análise geoestatística. A decisão sobre excluir ou não qualquer observação discrepante foi tomada, conforme descrito por Souza (2009). A normalidade dos dados foi verificada pelo teste de Kolmogorov-Smirnov $(\mathrm{p}<0,05)$.

Com a finalidade de comparar as médias dos valores dos atributos do solo na área sob vegetação natural em regeneração $(\mathrm{VN})$ com a da área em pastagem $(\mathrm{Pa})$, realizou-se o teste t-Student ( $\mathrm{p}<0,05)$, conforme descrito por Lima et al. (2009), quando da análise das frações granulométricas de solo.

\subsection{Análise geoestatística}

A geoestatística foi utilizada para verificar a existência e, nesse caso, quantificar o grau de dependência espacial dos atributos nas duas áreas, o que foi feito a partir do ajuste de funções teóricas aos modelos de semivariogramas experimentais, com base na pressuposição de estacionalidade da hipótese intrínseca e conforme a equação 1 .

$$
\gamma *(h)=\frac{1}{2 N(h)} \sum_{i=1}^{N(h)}\left[Z\left(x_{i}\right)-Z\left(x_{i}+h\right)\right]^{2}
$$

em que $\gamma^{*}(h)$ é a semivariância estimada e $N(h)$ é o número de pares de valores medidos $\mathrm{Z}\left(\mathrm{x}_{\mathrm{i}}\right)$ e $\mathrm{Z}\left(\mathrm{x}_{\mathrm{i}}+\mathrm{h}\right)$, separados por um vetor distância $h(\mathrm{~m})$.

Nos casos em que o patamar do semivariograma não foi definido foi feita a análise de tendência com os eixos $x$ e $y$ de todos os atributos, conforme descrito em Lima et al. (2010). Os modelos teóricos como o esférico, o exponencial e o gaussiano foram testados para o ajuste do semivariograma escalonado pela variância dos dados, para efeito de padronização da escala de semivariância, definindo-se os parâmetros: efeito pepita
$\left(\mathrm{C}_{0}\right)$, que reflete microestruturas ou variabilidade de pequena escala não captada para distâncias menores do que a menor entre as amostras; o patamar $\left(\mathrm{C}_{0}+\mathrm{C}\right)$, ponto onde o semivariograma se estabiliza e é aproximadamente igual à variância dos dados; variância estrutural (C); alcance da dependência espacial (a), distância na qual o semivariograma atinge o patamar e considera o limite da dependência espacial da grandeza; e índice de dependência espacial (IDE), que representa a relação da contribuição $\left(\mathrm{C}_{0}\right)$ pelo patamar $\left(\mathrm{C}_{0}+\mathrm{C}\right)$ na variabilidade dos dados. O IDE foi classificado conforme Cambardella et al. (1994) em baixo, médio e alto, para os intervalos: IDE $>75 \%, 25<$ IDEd"75\% e IDEd" $25 \%$, respectivamente.

A escolha do modelo teórico de semivariograma mais adequado foi baseada no maior coeficiente de determinação $\left(\mathrm{R}^{2}\right)$ e da menor soma de quadrados dos resíduos (SQR). No entanto, como critério definitivo, a escolha dos modelos foi com base na análise da validação cruzada, com a correlação significativa entre os valores observados e os estimados (vc).

Constatada a presença de dependência espacial dos atributos em cada parcela, realizou-se a interpolação pelo método da krigagem ordinária para estimar valores em locais não medidos. Essa técnica de interpolação estima valores sem tendenciosidade e com desvios mínimos em relação aos valores conhecidos (GREGO; VIEIRA, 2005).

\section{RESULTADOS}

\subsection{Análise exploratória e descritiva}

Nesta análise, identificaram-se os outliers, processou-se a remoção destes do conjunto de dados e, posteriormente, fez-se a determinação das medidas de posição e dispersão, bem como o teste t-Student $(\mathrm{p}<0,05)$ entre as médias dos atributos nas duas áreas (Tabela 1).

\subsection{Análise geoestatística}

Todos os semivariogramas apresentaram patamar definido, indicando que a hipótese intrínseca foi satisfeita e, portanto, os atributos não apresentaram tendência (Tabela 2).

Na Figura 1 estão apresentados os modelos de semivariogramas teóricos escalonados com melhor ajuste aos dados experimentais dos atributos de solo das

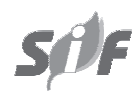

Revista Árvore, Viçosa-MG, v.37, n.3, p.539-546, 2013 
Tabela 1 - Estatística descritiva dos atributos do solo: argila dispersa em água (ADA), grau de floculação (GF) e matéria orgânica (MO), referentes às áreas de vegetação natural em regeneração (VN) e pastagem (Pa).

Table 1 - Descriptive statistics the attributes of soil clay dispersed in water, degree of flocculation of organic matter in a soil under regenerating natural vegetation and pasture.

\begin{tabular}{cccccccc}
\hline Atributos & $\mathrm{n}$ & Parcelas & $\bar{x}$ & Mín. & Máx. & CV & p-valor \\
\hline \multirow{2}{*}{ ADA $\left(\mathrm{g} \mathrm{kg}^{-1}\right)$} & 62 & $\mathrm{VN}$ & $194,0 \mathrm{~b}$ & 134,6 & 266,3 & 17,2 & $\mathrm{p}>0,20^{\mathrm{ns}}$ \\
& 63 & $\mathrm{~Pa}$ & $222,0 \mathrm{a}$ & 162,1 & 298,1 & 12,5 & $\mathrm{p}>0,20^{\mathrm{ns}}$ \\
\multirow{2}{*}{$\mathrm{GF}(\%)$} & 61 & $\mathrm{VN}$ & $55,0 \mathrm{a}$ & 31,3 & 68,7 & 16,7 & $\mathrm{p}>0,20^{\mathrm{ns}}$ \\
& 62 & $\mathrm{~Pa}$ & $46,3 \mathrm{~b}$ & 31,6 & 57,3 & 11,8 & $\mathrm{p}>0,20^{\mathrm{ns}}$ \\
\multirow{2}{*}{ MO $\left(\mathrm{g} \mathrm{kg}^{-1}\right)$} & 62 & $\mathrm{VN}$ & $25,7 \mathrm{a}$ & 19,5 & 30,9 & 10,9 & $\mathrm{p}>0,20^{\mathrm{ns}}$ \\
& 64 & $\mathrm{~Pa}$ & $25,2 \mathrm{a}$ & 18,0 & 34,4 & 17,0 & $\mathrm{p}>0,20^{\mathrm{ns}}$ \\
\hline
\end{tabular}

C. V area de vegetação natural em regeneração; Pa - área de pastagem; n - número de amostras; $\overline{\boldsymbol{x}}$ - média; $\mathrm{Ma}$

Médias de um mesmo atributo seguidas pela mesma letra na coluna não diferem significativamente pelo teste $\mathrm{t}-\mathrm{Student}(\mathrm{p}<0,05)$.

Tabela 2 - Análise geoestatística dos atributos do solo: argila dispersa em água (ADA), grau de floculação (GF) e matéria orgânica (MO), referentes às áreas de vegetação natural em regeneração (VN) e pastagem (Pa).

Table 2 - Geostatistics analysis of the attributes of soil: clay dispersed in water, degree of flocculation of organic matter in a soil under regenerating natural vegetation and pasture.

\begin{tabular}{|c|c|c|c|c|c|c|c|c|}
\hline Atributos & Modelo & $\mathrm{C}_{0}$ & $\mathrm{C}_{0}+\mathrm{C}$ & $\mathrm{a}(\mathrm{m})$ & IDE $(\%)$ & $\mathrm{R}^{2}(\%)$ & SQR & $\mathrm{vc}$ \\
\hline \multicolumn{9}{|c|}{ Vegetação natural em regeneração (VN) } \\
\hline $\mathrm{ADA}$ & Esf & 0,21 & 0,90 & 20 & 23 & 96 & 694 & $*$ \\
\hline GF & Exp & 0,30 & 0,90 & 35 & 33 & 99 & 2,00 & $*$ \\
\hline MO & Exp & 0,56 & 1,12 & 60 & 50 & 80 & 1,10 & $*$ \\
\hline \multicolumn{9}{|c|}{ Pastagem $(\mathrm{Pa})$} \\
\hline ADA & Exp & 0,21 & 0,95 & 30 & 22 & 82 & 1650 & $*$ \\
\hline GF & Exp & 0,44 & 1,06 & 50 & 42 & 97 & 1,52 & $*$ \\
\hline MO & Esf & 0,15 & 0,98 & 30 & 15 & 82 & 16,0 & $*$ \\
\hline
\end{tabular}

Esf. - modelo esférico; Exp. - modelo exponencial; $\mathrm{C}_{0}$ - efeito pepita; $\mathrm{C}_{0}+\mathrm{C}$ - patamar; a - alcance; IDE - índice de dependência espacial; $\mathrm{R}^{2}$ - coef. de determinação do semivariograma; $\mathrm{SQR}$ - soma de quadrados do resíduo; vc - nível de significância da validação cruzada; e * significativo $(\mathrm{p}<0,05)$.

duas áreas. O escalonamento padroniza a escala das semivariâncias, auxiliando na análise do padrão da distribuição espacial.

\subsubsection{Mapas de distribuição espacial dos atributos}

Comprovada a dependência espacial entre os dados dos atributos em estudo, foram realizadas interpolações, por meio da krigagem ordinária, de valores para locais não amostrados (Figura 2).

\section{DISCUSSÃO}

Todos os atributos (Tabela 1) apresentaram distribuição normal pelo teste de Kolmogorov-Smirnov $(\mathrm{p}<0,05)$ após a remoção dos outliers.

O solo sob VN apresentou o teor de GF significativamente superior (teste $t, p<0,05$ ) em relação ao ocupado por pastagem. A MO não apresentou diferença entre as duas áreas, fato esse que pode ter sido influenciado pelo formato da amostra de solo retirada e pela incorporação de resíduos no perfil do solo na profundidade estudada, por ocasião do seu revolvimento para implantação da pastagem. Esses resultados diferem dos encontrados por Souza et al. (2004) e Albuquerque et al. (2005), com maiores teores de MO em áreas de floresta nativa sem antropismo, devido ao maior aporte de resíduos orgânicos. O sistema radicular volumoso da Brachiaria decumbens acarreta aumento em profundidade, conforme relatado por Moreira e Siqueira (2002), o que também pode ter influenciado nas análises.

Os valores médios dos atributos indicam a existência de relação entre os teores de ADA e GF nas duas áreas. Como exemplo, o menor valor de ADA foi acompanhado de maior valor do GF na área sob VN, indicando maior

Revista Árvore, Viçosa-MG, v.37, n.3, p.539-546, 2013 

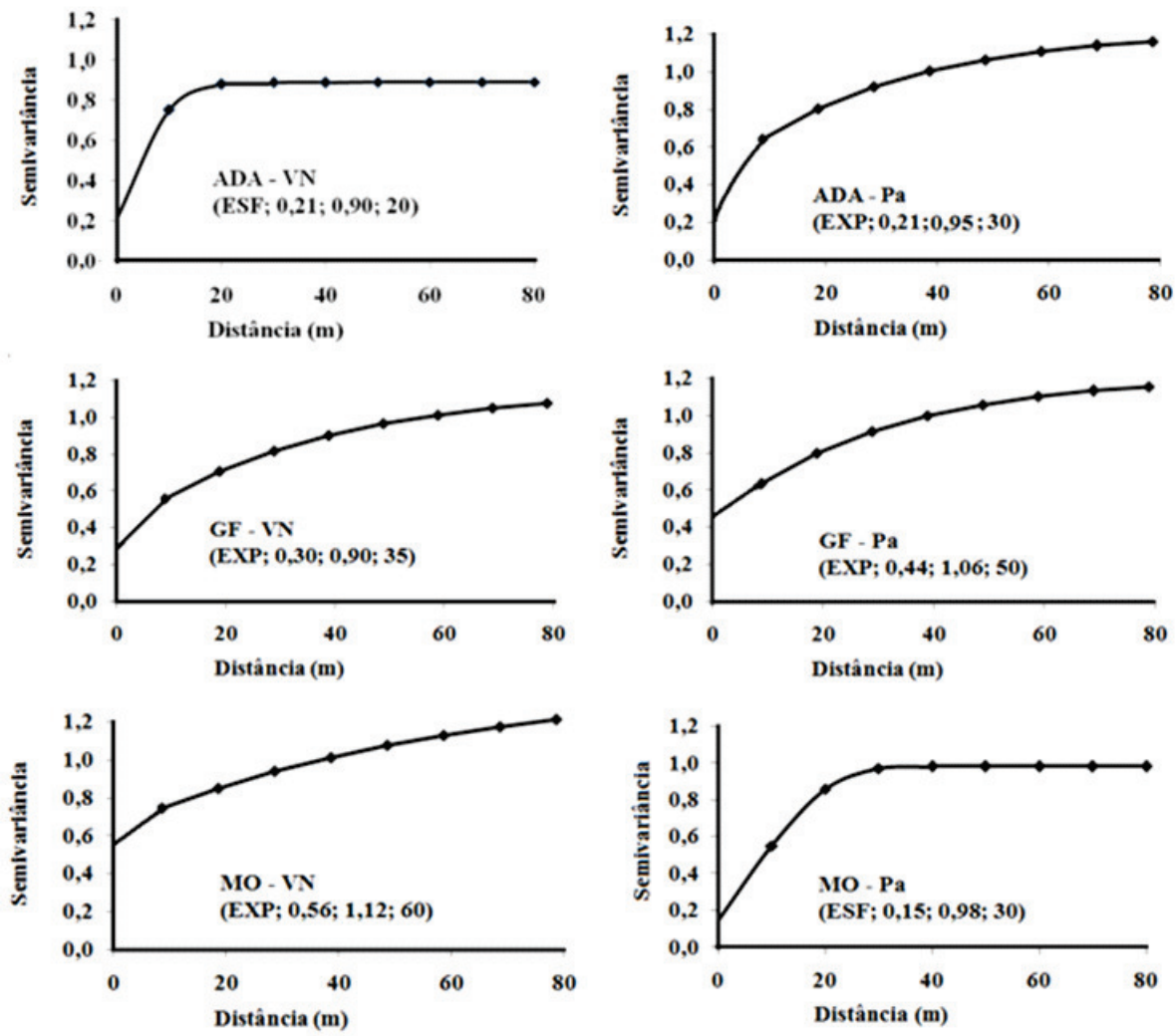

Figura 1 - Semivariogramas teóricos escalonados (Modelo; $\mathrm{C}_{0} ; \mathrm{C}_{0}+\mathrm{C} ;$ a) dos atributos do solo: argila dispersa em água (ADA), grau de floculação (GF) e matéria orgânica (MO), referentes às áreas de vegetação natural (VN) e pastagem (Pa).

Figure 1 -Standardized semivariograms theoretical (model; $C_{0} ; C_{0}+C ;$ a) the attributes of the soil: clay dispersed in water, degree of flocculation of organic matter in a soil under regenerating natural vegetation and pasture

agregação do solo sob vegetação natural. A ADA e o GF podem sofrer interferência de outros fatores, como a maior ou menor atividade bacteriana, decorrente dos níveis de acidez do solo (PRADO; NATALE, 2003).

A variabilidade dos dados medida pelos coeficientes de variação (CV) foi baseada nos limites propostos por Wilding e Drees (1983), indicando baixa variabilidade $(\mathrm{CV}<15 \%)$ na área sob Pa para ADA $(12,5 \%)$ e GF $(11,8 \%)$ e MO $(10,9 \%)$ na de VN; e moderada $(15 \%<\mathrm{C} \mathrm{V}<35 \%)$ na área sob VN para ADA $(17,2 \%)$ e GF $(16,7 \%)$ e MO $(17 \%)$ na de pastagem.

Apesar dos valores baixos e moderados de CV para a ADA, segundo Campos (2003) esse atributo apresentou valores elevados nas duas áreas para o tipo de solo estudado, textura argilosa, devido à expansão e contração quando exposto a umedecimento e secagem, como acontece com maior frequência na área de menor cobertura, que é a pastagem. Caracterizando, segundo Rosa Júnior et al. (2006), maior potencialidade ao arraste pelas águas das chuvas, bem como a compactação pelo pisoteio dos animais, contribuindo para aumentar os teores de ADA.

O teor de MO influencia na agregação das partículas do solo, bem como no GF (MULLER et al., 2001; PRADO e CENTURION, 2001). Dessa forma, a MO apresentou efeito de cimentação similar nas duas áreas, resultando em agregados estáveis no solo, apesar do maior teor de GF na VN.

Observou-se que o ajuste dos modelos permitiu construir semivariogramas com patamares bem definidos. Dessa forma, a hipótese intrínseca, que é exigência mínima para a análise geoestatística, foi atendida. $\mathrm{O}$ modelo teórico de semivariograma (Figura 1) que melhor se ajustou aos dados foi o esférico para a ADA na área

Revista Árvore, Viçosa-MG, v.37, n.3, p.539-546, 2013 

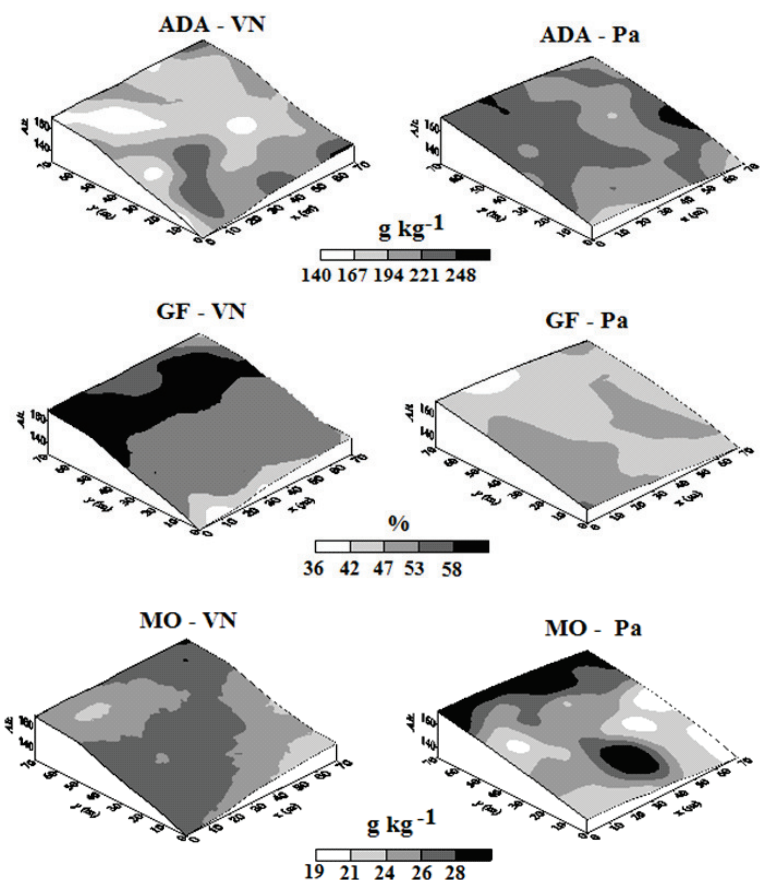

Figura 2 - Mapas de distribuição espacial dos atributos do solo: argila dispersa em água (ADA), grau de floculação (GF) e matéria orgânica (MO), referentes às áreas de vegetação natural (VN) e pastagem (Pa).

Figure 2-Maps of spatial distributions the attributes of the soil: clay dispersed in water, degree of flocculation of organic matter in a soil under regenerating natural vegetation and pasture.

de vegetação natural (VN) e para a MO na área de pastagem (Pa) e o exponencial para os demais atributos. De acordo com Mcbratney e Webster (1986), os modelos matemáticos que mais se ajustam aos atributos do solo são o esférico e o exponencial. Na Figura 1, dos semivariogramas teóricos escalonados pela variância dos dados, não se observa o mesmo padrão de distribuição espacial entre ADA e GF, a pesar de serem atributos relacionados.

Os modelos escolhidos apresentam $\mathrm{R}^{2}$ superior a $77 \%$, ou seja, a maior parte da variabilidade existente nos valores da semivariância estimada é explicada pelo modelo. De acordo com GS ${ }^{+}$(2004), a SQR é um parâmetro mais robusto do que o $\mathrm{R}^{2}$ e propicia uma medida mais exata do modelo que se ajusta aos dados, sendo os dois parâmetros usados na escolha do melhor modelo. Além desses parâmetros, foi considerado na escolha do melhor modelo a validação cruzada (vc), que informa a qualidade da estimativa por krigagem ordinária, sendo constatado que todos os modelos analisados apresentam valores significativos $(\mathrm{p}<0,05)$ entre os observados e os estimados na análise de regressão.

Com relação ao alcance da dependência espacial (a), observaram-se o menor valor para a ADA (20 m) e o maior para a MO $(60 \mathrm{~m})$, ambos na área sob VN. $\mathrm{O}$ maior alcance indica maior continuidade espacial de um atributo na área, como mostrado no menor CV para MO em VN. O valor do alcance define a distância máxima até onde o valor de um atributo possui relação de dependência espacial com o seu próximo. Assim, determinações realizadas com maior número de vizinhos no raio do alcance permite que se façam interpolações para espaçamentos menores que os amostrados com maior precisão na estimação.

$\mathrm{O}$ efeito pepita $\left(\mathrm{C}_{0}\right)$ representa a variância não explicada ou ao acaso, frequentemente causada por erros de medições ou variações dos atributos que não podem ser detectadas na escala de amostragem (VIEIRA, 2000). A área de pastagem ( $\mathrm{Pa}$ ) apresentou maiores valores de $\mathrm{C}_{0}$ para $\mathrm{ADA}$ e GF, enquanto a $\mathrm{MO}$ apresentou maior valor na área de vegetação natural (VN). A magnitude do $\mathrm{C}_{0}$ é importante na krigagem, pois, quanto menor sua contribuição em relação à variabilidade dos dados, maior a continuidade do fenômeno e menor a variância da estimativa (ISAAKS; SRIVASTAVA, 1989). Quanto menor a proporção do $\mathrm{C}_{0}$ em relação ao patamar do semivariograma, maior a dependência espacial apresentada pelo atributo (CAMBARDELLA et al., 1994); com isso, maior a continuidade do fenômeno, menor a variância da estimativa e maior a confiança no valor estimado (LIMA et al., 2006).

A análise do índice de dependência espacial (IDE) representa, dessa forma, a contribuição da dependência espacial no ajuste do modelo teórico em relação à variabilidade total dos dados. Todos os atributos apresentam IDE superior ou igual a 50\%. De acordo com Cambardella et al. (1994), o IDE foi classificado em forte para ADA nas duas áreas e para a MO na área sob pastagem $(\mathrm{Pa})$ e em moderado para os demais atributos.

Analisando os mapas de distribuição espacial (Figura 2), verificou-se relação entre o tipo de cobertura vegetal e o relevo declivoso das áreas para a distribuição espacial da ADA, do GF e da MO. Na área sob VN, na parte inferior esquerda do terreno ocorre uma zona de deposição de partículas, provenientes do escoamento 
superficial, com maior concentração dos maiores teores de ADA, mostrando a influência da mudança da pedoforma convexa para côncava. O inverso ocorre para o GF nessa região. A área sob Pa com pedoforma côncava apresenta as laterais com maior concentração de ADA, mostrando maior dispersão em superfície, comparativamente com a de VN. Observou-se na área de VN a correlação espacial negativa da ADA com o GF, ou seja, baixa concentração de ADA e alta concentração de GF na região superior da área.

Para os teores de MO, observou-se comportamento espacial distinto entre as duas áreas, apresentando maior amplitude na área sob $\mathrm{Pa}$, concordando com o maior valor de CV. Dessa forma, ao considerar uma parcela experimental uniforme quanto aos seus atributos, mesmo em pequenas áreas, podem-se interpretar erroneamente as respostas obtidas às questões existentes, pois a ocorrência de dependência espacial estará sendo ignorada (GREGO; VIEIRA, 2005).

\section{CONCLUSÕES}

Todos os atributos apresentam dependência espacial nas duas áreas em estudo, com ajuste do modelo esférico e exponencial. O menor alcance foi observado para argila dispersa em água (ADA) (20 m) e maior para a matéria orgânica (MO) (60 m) para a área de vegetação natural em regeneração.

A argila dispersa em água (ADA) apresentou correlação espacial negativa com o grau de floculação (GF) na área de vegetação natural em regeneração (VN).

Os atributos estudados variaram espacialmente de forma significativa entre as áreas de mesma unidade taxonômica sob diferentes coberturas.

\section{REFERÊNCIAS}

ALBUQUERQUE, J. A. et al. Relationship of soil attributes with aggregate stability of a hapludox under distinct tillage systems and Summer cover crop. Revista Brasileira de Ciência do Solo, Campinas, v.29, n.3, p. 415-424. 2005.

CAMBARDELLA, C. A.; MOORMAN, T.B.; NOVAK, J. M.; PARKIN, T. B.; KARLEN, D. L.; TURCO, R. F.; KONOPKA, A. E. Field-scale variability of soil properties in central Iowa soils. Soil Science Society America Journal, v.58, p.1501-1511. 1994.
CORÁ, J. E. et al. Variabilidade espacial de atributos do solo para adoção do sistema de agricultura de precisão na cultura de cana-deaçúcar. Revista Brasileira de Ciência do Solo, Viçosa, v.28, n.6, p.1013-1021, 2004.

CENTURION, J. F. et al. Efeitos de forma de manejo em algumas propriedades físicas e químicas de um Latossolo Vermelho-Amarelo em diferentes agroecossistemas. Revista Brasileira de Engenharia Agrícola e Ambiental, Campina Grande, v.5, n.2, p. 254-258, 2001.

EMBRAPA - EMPRESA BRASILEIRA DE PESQUISA AGROPECUÁRIA. Manual de Métodos de Análise do Solo. 2. ed. Rio de Janeiro: Centro Nacional de Pesquisas de Solos, 1997. $212 \mathrm{p}$.

EMBRAPA - EMPRESA BRASILEIRADE PESQUISA AGROPECUÁRIA. Sistema Brasileiro de Classificação de Solos. 2. ed. Rio de Janeiro: EMBRAPA/CNPS, 2006. 3006p.

EMBRAPA - EMPRESA BRASILEIRADE PESQUIS A AGROPECUÁRIA. Manual de análises químicas de solos, plantas e fertilizantes. Brasília: CNPTIA, 1999. 370p.

GAMMA DESIGN SOFTWARE. GS ${ }^{+\circledast}$ -

Geostatistics for the Environmental Sciences. Version 7.0. Michigan: 2004. 1 CDROM.

GOMES, N. M. et al. Variabilidade espacial de atributos físicos do solo associados ao uso e ocupação da paisagem. Revista Brasileira de Engenharia Agrícola e Ambiental, Campina Grande, v.11, n.4, p.427-435, 2007.

GREGO, C. R.; VIEIRA, S. R. Variabilidade espacial de propriedades físicas do solo em uma parcela experimental. Revista Brasileira de Ciência do Solo, Viçosa, v.29, n.2, p.169-177, 2005.

ISAAKS, E. H.; SRIVASTAVA, R. M. An introduction to applied geoestatistics. New York: Oxford University, 1989. 561p.

LIMA, J. S. S. et al. Estudo da viabilidade de métodos geoestatísticos na mensuração da variabilidade espacial da dureza da madeira de Paraju (Manilkara sp.). Revista Árvore, v.30, n.4, p.651-657, 2006.

Revista Árvore, Viçosa-MG, v.37, n.3, p.539-546, 2013 
LIMA, J. S. S. et al. Variabilidade espacial da textura de um Argissolo Vermelho Amarelo sob cultivo de pastagem e vegetação nativa.

Ciência Rural. Santa Maria, v.39, n.09, p.2634-2637. 2009.

LIMA, J. S. S. et al. Amostragem e variabilidade espacial de atributos químicos do solo em área de vegetação natural em regeneração. Revista Árvore, v.34, n.1, p.127-136. 2010.

McBRATNEY, A. B.; WEBSTER, R. Choosing functions for semi-variograms of soil properties and fitting them to sampling estimates. Journal of Soil Science, v.37, n.4, p.617-639, 1986.

MOREIRA, F. M.; S.; SIQUEIRA, J. O.

Microbiologia e bioquímica do solo. Lavras: UFLA, 626p. 2002.

MULLER, M. M. L. et al. Degradação de pastagens na Região Amazônica: propriedades físicas do solo e crescimento de raízes.

Pesquisa Agropecuária Brasileira, Brasília, v.36, n.11, p.1409-1418, 2001.

PRADO, R. M.; CENTURION, J. F. Alterações da cor e no grau de floculação de um Latossolo Vermelho-Escuro sob cultivo de cana-de-açúcar. Pesquisa Agropecuária Brasileira, v. 36, n1,p.197-203. 2001.

PRADO, R. M.; NATALE. W. Alterações na granulometria, grau de floculação e propriedades químicas e de um Latossolocor e no grau de floculação de um Latossolo Vermelho Distrófico, sob plantio direto e reflorestamento. Acta Scientiarium: Agronomy, Maringa, v.25, n.1, p.45-52, 2003.
ROSA JUNIOR, E. J. et al. Calcário e gesso como condicionantes físico e químico de um solo de cerrado sob três sistemas de manejo. Pesquisa Agropecuária Tropical, Goiânia, v.36, n.1, p.37-44, 2006.

SOUZA, Z. M.; LEITE, J. A.; BEUTLER, A.N. Comportamento de atributos físicos de um Latossolo Amarelo sob agroecossistemas do Amazonas. Engenharia Agrícola, Jaboticabal, v.24, n.3, p.654-662, 2004.

SOUZA, G. S. Uso de indicadores de fertilidade do solo na análise da degradação de uma área sob pastagem utilizando geoestatística. 2009. 98.f. Dissertação (Mestrado em produção Vegetal)Centro de Ciências Agrárias, Universidade Federal do Espírito Santo. Alegre, 2009.

VIEIRA, S. R. Geoestatística em estudos de variabilidade espacial do solo. In: NOVAIS, P.F.; ALVAREZ, V.H.; SCHAEFER, C.E.G.R. Tópicos em ciência do solo. Viçosa: Sociedade Brasileira de Ciência do Solo, 2000. v.1. p.1-54.

YEOMANS, J. C.; BREMNER, J.M. Araid precise method for routine determination of organic carbon in soil. Communication in Soil Science and Plant Analysis, v.19, n.13, p. $1467-1476,1988$.

WILDING, L. P.; DREES, L. R. Spatial variability and pedology. In: WILDING, L. P.; DREES, L. R. (Eds.). Pedogenesis and soil taxonomy: concepts and interactions. New York: Elsevier, 1983. p.83-116. 